\title{
Outcome of Concurrent Chemoradiotherapy and Radiotherapy Alone Following Induction Chemotherapy in Locally Advanced Squamous Cell Carcinoma of Head and Neck
}

\author{
Bari $\mathrm{MA}^{1^{*}}$, Alam $\mathrm{S}^{1}$, Sharmin $\mathrm{S}^{1}$, Shamsunnahar ${ }^{2}$, Uddin $\mathrm{J}^{1}$, Alam $\mathrm{N}^{1}$ \\ ${ }^{1}$ Department of Oncology, Bangabandhu Sheikh Mujib Medical University, Dhaka, Bangladesh \\ ${ }^{2}$ Family Welfare Centre, Bason, Sadar, Gazipur, Bangladesh
}

\begin{abstract}
Non-operative treatment strategies like radiotherapy and chemotherapy are practiced widely nowadays for the treatment of locally advanced squamous cell carcinoma of head and neck origin. Aim of this study was to compare the response of induction chemotherapy followed by radiotherapy alone with induction chemotherapy followed by concurrent chemoradiotherapy in terms of treatment response and toxicities. A quasi-experimental study was carried out in the Department of Radiation Oncology, National Institute of Cancer Research and Hospital (NICR\&H), Dhaka; Department of Radiotherapy, Dhaka Medical College Hospital (DMCH), Dhaka and Department of Oncology, Bangabandhu Sheikh Mujib Medical University (BSMMU), Dhaka during the period of January, 2014 to December, 2014. Induction chemotherapy by Cisplatin and 5-Fluorouracil was given to all the patients of Arm A and Arm B. Cisplatin was given concurrently during Radiotherapy weekly in case of Arm A. Arm B received radiotherapy alone. The patients were evaluated from the beginning of the treatment up to six months following the completion of treatment. In this study, male to female ratio was $4: 1$ and mean age of patients were $54.7 \pm 9.1$ and $56.6 \pm 7.9$ in Arm A and Arm B respectively. At final follow-up, complete response was seen in 27 (53.3\%) patients of Arm A and Arm B respectively. Response rate was significant $(p<0.05)$ for both the Arms. Acute toxicities observed during induction chemotherapy were almost equal in both the Arms, but during radiotherapy, Arm A had more toxicity though it was statistically insignificant. Induction chemotherapy followed by concurrent chemoradiotherapy is more effective than induction chemotherapy followed by radiotherapy alone in locoregional control of locally advanced squamous cell carcinoma of head and neck origin.
\end{abstract}

Keyword: Concurrent chemoradiotherapy; Induction chemotherapy; Squamous Cell carcinoma

\section{Introduction}

Cancer is one of the major causes of morbidity and mortality among the non-communicable diseases in Bangladesh. Cancer is the sixth cause of mortality in Bangladesh and more than half of the cancer patients die within five years of diagnosis. Cancer load is more than 1,200,000 in Bangladesh. ${ }^{1-2}$

Head and neck Cancer is the name given to a variety of malignant tumors that develop in the head and neck region. Among them, the vast majority arises from the surface epithelium and are, therefore, squamous cell carcinoma (about 90\%) or one of its many variants. ${ }^{3}$ Cancers of the brain, the eye, the esophagus, and the thyroid gland, as well as those of the scalp, skin, muscles, and bones of the head and neck, are not usually classified as head and neck cancers. ${ }^{4}$

Unlike the developed countries, there is no complete statistics of head and neck cancer in our country. But according to some institution based studies done in 1990 among 3399 new cancer patients who attended the Department of Radiotherapy, DMCH, revealed head and neck cancer is about $33.15 \%$ of all malignancies in male, $20.78 \%$ in female and $28.68 \%$ in all the malignancies in both the sexes. ${ }^{5}$

Despite advancement of surgical techniques, the overall morbidity and mortality associated with resection of advanced head and neck cancer remains substantially high. Nonoperative treatment strategies with radiation and chemotherapy are practiced frequently. The basic principle of radiotherapy is to cure the patients with minimal functional and structural impairment. Small primary lesions (T1 and T2) with negative cervical nodes are generally treated with single modality approach. Small lesions with nodal involvement 
require both surgery and irradiation for the control of the neck disease. Large primary lesions (T3 and T4) with or without extension to the cervical nodes usually need both surgery and radiotherapy. Sometimes surgery is not possible due to involvement of certain anatomical sites and some associated medical co-morbidities, then the choice of treatment is radiotherapy (RT) and chemotherapy with comparable results. Considering the results of treatment, morbidity and mortality of surgery, preservation of organ and cosmesis, radiotherapy is preferred to surgery. ${ }^{6-9}$

Several prognostic factors have been identified for patients with head and neck cancer. Particularly age older than 70 years has been identified as an unfavorable predictor of outcome. This may simply reflect the less likelihood of elderly patients to successfully tolerate the aggressive therapy. In addition, tumor location has an impact on outcome. The extent of the primary lesion and neck disease are the major determinants of prognosis. The likelihood of loco-regional control is affected primarily by the overall American Joint Committee on Cancer (AJCC) stage, which accounts for both T stage and $\mathrm{N}$ stage. T-category is associated with worse local control and overall survival; advanced $\mathrm{N}$-category predicts increased risk of distant metastasis and worse survival. The grade of a cancer is a qualitative assessment of the degree of differentiation of the tumor. Least differentiation associated with the better response to chemotherapy and radiotherapy. ${ }^{9-10}$

The use of concurrent chemoradiotherapy (CCRT) for most stage III and IV (nonmetastatic) oropharyngeal cancer patients is based on the results of the meta-analysis of chemotherapy in head and neck cancer (MACH-NC), which demonstrated a $6.2 \%$ absolute improvement in overall survival at 5 years from the use of concurrent chemoradiotherapy compared to radiotherapy alone. Combined modality therapy was associated with increased mucositis, hematological toxicity and weight loss. But all these adverse effects are easily manageable. ${ }^{9}$

In this country, practice of induction chemotherapy followed by concurrent chemoradiotherapy is not frequently used due to the fear of increased toxicity. The aim of this study is to compare the outcome of Concurrent Chemoradiotherapy with Radiotherapy alone following Induction Chemotherapy Advanced Squamous Cell Carcinoma of Head and Neck in terms of response and toxicities.

\section{Material and Methods}

This was Quasi-Experimental study to compare the treatment outcome of Chemoradiotherapy with Radiotherapy alone following induction chemotherapy in locally advanced squamous cell carcinoma of head and neck origin. The study was conducted at the Department of Oncology, Bangabandhu Sheikh Mujib Medical University (BSMMU), Department of Radiotherapy, Dhaka Medical College and Hospital (DMCH) and Department of Radiation Oncology, National Institute of Cancer Research and Hospital (NICRH), Dhaka from January 2014 to December 2014.

Initially, patients were selected purposively who met the set inclusion criteria. Then patients were enrolled in either Arm A or Arm B in alternate manner. Inclusion criteria for this study were, clinically diagnosed and histopathologicaly proven squamous cell carcinoma of any head and neck sub site, American Joint Committee on Cancer $7^{\text {th }}$ edition (AJCC) stage III to IVB with Eastern Cooperative Oncology Group (ECOG) performance status $0-2$ and no history of prior chemotherapy, radiotherapy or surgery. Informed written consent was taken from all participated patients.

Arm A consisted of 30 patients who received the induction chemotherapy followed by concurrent chemoradiotherapy and Arm B included another 30 patients those who received induction chemotherapy followed by radiotherapy alone.

Induction policy was adopted for both the arms with injection Cisplatin $100 \mathrm{mg} / \mathrm{m} 2 /$ day IV on day 1 and injection $5-\mathrm{Fu}, 1000 \mathrm{mg} / \mathrm{m} 2 /$ day IV on day 1 to 4 , three weekly cycle for 3 cycles. Weekly injection Cisplatin $30 \mathrm{mg} / \mathrm{m} 2$ IV was given during CCRT. Radiotherapy dose was 66 By in 33 daily fractions over 6.5 weeks for both the arms A and B. Every patient was evaluated after each cycle of chemotherapy and weekly thereafter. They were also evaluated at 6, 18 and 30 weeks after completion of treatment. 
Every patient was evaluated three weeks after each cycle of induction chemotherapy, weekly during radiotherapy, thereafter at week 6,12 and 6 months after completion of treatment. Response was evaluated by WHO recist criteria vl.1 and toxicities were measured according to CTC AE v3.0. ${ }^{11,12}$

Data were collected and analyzed in Statistical Package for Social Sciences (SPSS) version 21. A $p$-value of less than 0.05 was taken as statistically significant. Patient characteristics were compared by ' $z$ ' test and independent ' $t$ ' test, the chi-square test was used to compare the treatment response and toxicities.

\section{Results}

During January 2014 to December 2014, a total of 60 patients were included in this study. Thirty patients were included in Arm A and thirty patients in Arm B. Mean age of patients were 54.7 \pm 9.1 and 56.6 \pm 7.9 in Arm A and Arm B respectively. Overall male female ratio was 4:1 (table I).

Table I: Patient characteristics.

\begin{tabular}{|c|c|c|c|c|}
\hline Characteristics & $\begin{array}{l}\operatorname{Arm} \mathbf{A} \\
(\mathbf{n}=30)\end{array}$ & $\begin{array}{l}\text { Arm B } \\
(n=30)\end{array}$ & $\begin{array}{c}\text { Total } \\
(\mathbf{n}-60)\end{array}$ & $\begin{array}{c}p \\
\text { Value }\end{array}$ \\
\hline \multicolumn{5}{|l|}{ Sex } \\
\hline Male & 23 & 25 & 48 & 0.516 \\
\hline Female & 7 & 5 & 12 & \multirow[t]{2}{*}{0.516} \\
\hline $\mathrm{M}: \mathrm{F}$ & $3.2: 1$ & $5: 1$ & $4: 1$ & \\
\hline \multicolumn{5}{|l|}{ Age } \\
\hline Mean & 54.7 & 56.6 & & \multirow{2}{*}{0.385} \\
\hline SD & \pm 9.1 & \pm 7.9 & & \\
\hline \multicolumn{5}{|c|}{ ECOG Performance status } \\
\hline $0-1$ & $\begin{array}{c}19 \\
(63.3 \%)\end{array}$ & $17(56.7 \%)$ & 36 & \multirow[b]{2}{*}{0.596} \\
\hline 2 & $\begin{array}{c}11 \\
(36.7 \%)\end{array}$ & $13(43.3 \%)$ & 24 & \\
\hline \multicolumn{5}{|l|}{ Stage } \\
\hline III & $\begin{array}{c}17 \\
(56.7 \%)\end{array}$ & $18(60.0 \%)$ & 35 & \\
\hline IV A & $\begin{array}{c}11 \\
(36.6 \%)\end{array}$ & $11(36.7 \%)$ & 22 & 0.795 \\
\hline IV B & $2(6.7 \%)$ & $1(3.3 \%)$ & 3 & \\
\hline \multicolumn{5}{|c|}{ Histological Grading } \\
\hline $\begin{array}{l}\text { Well } \\
\text { differentiated }\end{array}$ & $\begin{array}{c}15 \\
(50.0 \%)\end{array}$ & $14(46.7 \%)$ & 29 & 0.795 \\
\hline $\begin{array}{l}\text { Moderately } \\
\text { differentiated }\end{array}$ & $\begin{array}{c}13 \\
(43.3 \%)\end{array}$ & $12(40.0 \%)$ & 25 & 0.795 \\
\hline $\begin{array}{l}\text { Poorly } \\
\text { Differentiated }\end{array}$ & $2(6.7 \%)$ & $4(13.3 \%)$ & 6 & 0.39 \\
\hline
\end{tabular}

Note: $\mathrm{M}: \mathrm{F}$ - male to female ratio; $\mathrm{SD}$ - Standard deviation.

Toxicities observed during induction chemotherapy. None of the patient developed any grade 4 toxicity. Also there was no statistically significant grade $2-3$ toxicity observed (table II).

Acute toxicities observed during radiotherapy and no patient was found to be developed any grade 4 toxicity (table III).
Table II: Toxicities observed during induction chemotherapy.

\begin{tabular}{|c|c|c|c|}
\hline Toxicity & $\begin{array}{c}\operatorname{Arm~A} \\
(n=30)\end{array}$ & $\begin{array}{c}\operatorname{Arm~B} \\
(n=30)\end{array}$ & $\begin{array}{c}p \\
\text { Value } \\
\end{array}$ \\
\hline \multicolumn{4}{|l|}{ Anaemia } \\
\hline Grade 2 & $5(16.7 \%)$ & $6(20 \%)$ & \multirow{2}{*}{0.515} \\
\hline Grade 3 & $2(6.7 \%)$ & $1(3.3 \%)$ & \\
\hline \multicolumn{4}{|l|}{ Neutropenia } \\
\hline Grade 2 & $3(10 \%)$ & $2(6.7 \%)$ & \multirow{2}{*}{0.465} \\
\hline Grade 3 & $1(3.3 \%)$ & $1(3.3 \%)$ & \\
\hline \multicolumn{4}{|c|}{ Thrombocytopenia } \\
\hline Grade 2 & $2(6.7 \%)$ & $1(3.3 \%)$ & \multirow{2}{*}{0.248} \\
\hline Grade 3 & $0(0 \%)$ & $1(3.3 \%)$ & \\
\hline \multicolumn{4}{|l|}{ Nephrotoxicity } \\
\hline Grade 2 & $3(10 \%)$ & $2(6.7 \%)$ & \multirow{2}{*}{0.273} \\
\hline Grade 3 & $0(0 \%)$ & $1(3.3 \%)$ & \\
\hline \multicolumn{4}{|l|}{ Vomiting } \\
\hline Grade 2 & $6(20 \%)$ & $5(16.7 \%)$ & \multirow{2}{*}{0.155} \\
\hline Grade 3 & $0(0 \%)$ & $2(6.7 \%)$ & \\
\hline \multicolumn{4}{|l|}{ Diarrhoea } \\
\hline Grade 2 & $3(10 \%)$ & $2(6.7 \%)$ & \multirow{2}{*}{0.465} \\
\hline Grade 3 & $1(3.3 \%)$ & $0(0 \%)$ & \\
\hline \multicolumn{4}{|l|}{ Oral Mucositis } \\
\hline Grade 2 & $3(10 \%)$ & $3(10 \%)$ & \multirow{2}{*}{0.35} \\
\hline Grade 3 & $1(3.3 \%)$ & $0(0 \%)$ & \\
\hline
\end{tabular}

Table III: Toxicities observed during radiotherapy.

\begin{tabular}{lccc}
\hline \multicolumn{1}{c}{ Toxicity } & $\begin{array}{c}\text { Arm A } \\
(\mathbf{n = 3 0})\end{array}$ & $\begin{array}{c}\text { Arm B } \\
(\mathbf{n = 3 0})\end{array}$ & $\begin{array}{c}\boldsymbol{p} \\
\text { Value }\end{array}$ \\
\hline Oral Mucositis & $12(40 \%)$ & $16(53.3 \%)$ & \\
Grade 2 & $10(33.3 \%)$ & $5(16.7 \%)$ & 0.317 \\
Grade 3 & $3(10 \%)$ & $2(6.7 \%)$ & \\
Xerostomia & $1(3.3 \%)$ & $2(6.7 \%)$ & 0.766 \\
Grade 2 & $7(23.3 \%)$ & $2(6.7 \%)$ & \\
Grade 3 & $3(10 \%)$ & $1(3.3 \%)$ & 0.089 \\
Dermatitis & $3(10 \%)$ & $2(6.7 \%)$ & \\
Grade 2 & $0(0 \%)$ & $1(3.3 \%)$ & 0.737 \\
Grade 3 & & & \\
Anaemia & $6(20 \%)$ & $5(16.7 \%)$ & 0.348 \\
Grade 2 & $2(6.7 \%)$ & \\
Grade 3 & & \\
Vomiting & $0(0 \%)$ & $2(6.7 \%)$ & 0.548 \\
Grade 2 & $0(0 \%)$ & \\
Grade 3 & & & \\
Diarrhoea & $3(10 \%)$ & \\
Grade 2 & $1(3.3 \%)$ & & \\
Grade 3 & &
\end{tabular}

Response assessed at final follow-up after 6 months of treatment (table IV and figure 1). Complete response was seen in $27(90.0 \%) 16(53.03 \%)$ patients of Arm A and Arm B respectively. This difference was statistically significant $(p<0.05)$.

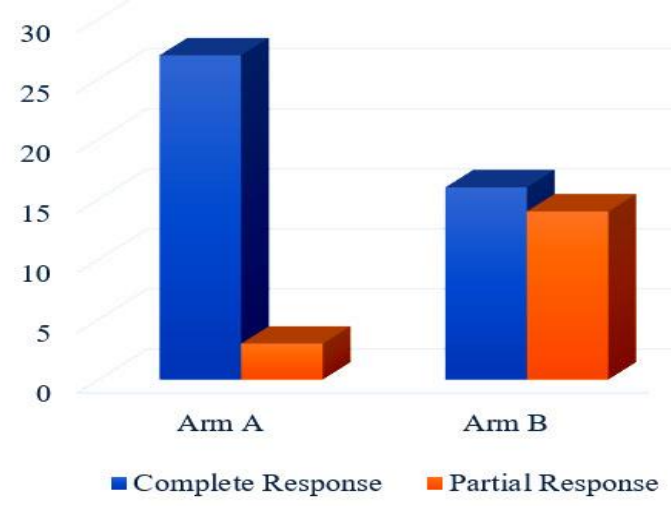

Figure 1: Response assessed at final follow-up (6 months after treatment) 
Table IV: Response assessed at final follow-up (6 months after treatment)

\begin{tabular}{lccc}
\hline \multicolumn{1}{c}{ Response } & Arm A & Arm B & $\boldsymbol{p}$ Value \\
\hline Complete Response & $27(90 \%)$ & $16(53.3 \%)$ & \multirow{2}{*}{0.002} \\
Partial response & $3(10 \%)$ & $14(46.7 \%)$ & \\
\hline
\end{tabular}

\section{Discussion}

Management of locally advanced squamous cell carcinoma of head and neck region is based on multimodality treatment. Current standard for all the sub-sites of head-neck region (except nasopharynx) is either definitive chemoradiotherapy or surgery followed by post operative radiotherapy. ${ }^{13}$ This principle is not always feasible for most of the patients due to increased toxicity of definitive chemoradiotherapy and morbidities of surgery. ${ }^{14}$

Induction chemotherapy followed by radiotherapy is a good alternative to above mentioned management approach. Here induction chemotherapy gives the benefit of tumor shrinkage as well as gives the prediction about the sensitivity of tumor for radiotherapy. ${ }^{15}$ Furthermore, updates of studies have shown increased rate of metastatic recurrence despite good loco-regional control with concurrent chemoradiotherapy alone. ${ }^{16}$

In this study, concurrent chemoradiotherapy (ArmA) following induction chemotherapy was associated with higher rate of complete response (90.0\% versus $53.3 \%$ ) than radiotherapy alone (Arm-B). This observed difference was statically significant $(p=0.002)$. in support of this finding, Forastiere et al showed that, induction chemotherapy followed by radiotherapy alone produced locoregional control rate of 75.0 percent (95.0 percent confidence interval, 61.0 to 81.0 percent). ${ }^{17}$ On the other hand, Haddad et al revealed that, induction chemotherapy followed by concurrent chemoradiotherapy in locally advanced carcinoma of head and neck had $73 \%$ (95\% CI 6082) 3 year overall survival. ${ }^{18}$ Although current study dealt with the short term outcomes, its observations correlate with the trend of the mentioned study findings. This study also correlates with the results of MACH-NC. ${ }^{19}$

Considering toxicity, during induction chemotherapy, acute toxicities observed in both Arm A and Arm B was almost same and there was no statistically significant difference observed. But, acute toxicities during and immediately after radiotherapy were significantly more with concurrent chemoradiotherapy (Arm A). Grade 3 mucositis was observed in $10(33.3 \%)$ and 5 (16.7\%) patients of Arm A and B respectively, which also correlates with the observations of Hitt et al, where $45(39.5 \%)$ patients with concurrent chemoradiotherapy had Grade 3 mucositis. ${ }^{20}$ Though the rate of acute toxicities were higher, they were managed accordingly.

\section{Conclusion}

Induction chemotherapy followed by concurrent chemoradiotherapy is more effective than that of induction chemotherapy followed by radiotherapy alone in loco-regional control of locally advanced squamous cell carcinoma of head and neck.

\section{Reference}

1. Ministry of Health and Family Welfare. National Cancer Control Strategy and Plan of Action, 20092015, Dhaka: Directorate General of Health Services; 2011 p. 6.

2. GLOBOCAN 2008: Cancer Incidence and Mortality Worldwide [Internet]. Iarc.fr. 2016 [cited 5 November 2016].

3. Bomford C, Kunkler I, Walter J. Walter and Miller's textbook of radiotherapy. 6th ed. Edinburgh: Churchill Livingstone; 2003:342-43.

4. Chao K, Perez C, Brady L. Radiation oncology: Management Decisions. 3rd ed. Philadelphia: Wolters Kluwer Health/Lippincott Williams \& Wilkins; 2011:88-89.

5. Sarma S. et al. Distribution pattern of 3399 new cancer patients- A one yera study. Bangladesh Medical Journal. 1992;25:5.

6. Adelstein DJ, Li Y, Adams GL, Wagner H, Kish JA, Ensley JF, Schuller DE, Forastiere AA. An intergroup phase III comparison of standard radiation therapy and two schedules of concurrent chemoradiotherapy in patients with unresectable squamous cell head and neck cancer. Journal of Clinical Oncology. 2003;21:92-98.

7. Adelstein DJ. Induction chemotherapy in head and neck cancer. Hematology/oncology clinics of North America. 1999;13:689-98.

8. Halperin E, Wazer D, Brady L, Perez C. Perez and Brady's principles and practice of radiation oncology. 6th ed. Philadelphia: LWW; 2013:718-19.

9. Vokes EE, Kies MS, Haraf DJ, Stenson K, List M, Humerickhouse R, Dolan ME, Pelzer H, Sulzen L, Witt ME, Hsieh YC. Concomitant chemoradiotherapy as primary therapy for locoregionally advanced head and neck cancer. Journal of Clinical Oncology. 2000;18:1652-61.

10. Rubin P. Clinical oncology. 8th ed. Philadelphia: W.B. Saunders Co.; 2001.

11. Trotti A, Colevas A, Setser A, Rusch V, Jaques D, Budach V et al. CTCAE v3.0: development of a comprehensive grading system for the adverse effects of cancer treatment. Seminars in Radiation Oncology. 2003;13:176-181. 
12. Nishino M, Jagannathan J, Ramaiya N, Van den Abbeele A. Revised RECIST Guideline Version 1.1: What Oncologists Want to Know and What Radiologist Need to Know. American Journal of Roentgenology. 2010;195:281-289.

13. Gregoire V, Lefebvre J, Licitra L, Felip E. Squamous cell carcinoma of the head and neck: EHNS-ESMO-ESTRO Clinical Practice Guidelines for diagnosis, treatment and follow-up. Annals of Oncology. 2010;21:184-186.

14. Machtay M, Moughan J, Trotti A, Garden A, Weber $\mathrm{R}$, Cooper J et al. Factors Associate With Severe Late Toxicity After Concurrent Chemoradiation for Locally Advanced Head and Neck Cancer: An RTOG Analysis. Journal of Clinical Oncology. 2008;26:3582-3589.

15. Hanna N. Phase III Study Comparing Cisplatin Plus Fluorouracil to Paclitaxel, Cisplatin and Fluorouracil Induction Chemotherapy Followed by Chemoradiotherapy in Locally Advanced Head and Neck Cancer. Year Book of Oncology. 2007;221222.

16. Brockstein B. Patterns of failure, prognostic factors and survival in locoregionally advanced head and neck cancer treated with concomitant chemoradiotherapy: a 9-year, 337-patient, multi- institutional experience. Annals of Oncology. 2004;15:1179-1186.

17. Forastiere A, Goepfert H, Maor M, Pajak T, Weber $\mathrm{R}$, Morrison W et al. Concurrent Chemotherapy and Radiotherapy for Organ Preservation in Advanced Laryngeal Cancer. New England Journal of Medicine. 2003;349:2091-2098.

18. Hadda R, O’Neill A, Rabinowits G, Tishler R, Khuri $\mathrm{F}$, Adkins $\mathrm{D}$ et al. induction chemotherapy followed by concurrent chemoradiotherapy (sequential chemoradiotherapy) versus concurrent chemoradiotherapy alone in locally advanced head and neck cancer (PARADIGM): a randomised phase 3 trial. The Lancet Oncology.2013;14:257-264.

19. Blanchard P, Baujat B, Holostenco V, Bourredjem A, Baey C, Bourhis $\mathrm{J}$ et al. Meta-analysis of chemotherapy in head and neck cancer (MACHNC): A comprehensive analysis by tumour site. Radiotherapy and Oncology. 2011;100:33-40.

20. Hitt R, Grau J, Lopez-Pousa A, Berrocal A, GarciaGiron C, Irigoyen a et al. A randomized phase III trial comparing induction chemotherapy followed by chemotherapy versus chemoradiotherapy alone as treatment of unresectable head and neck cancer. Annals of Oncology.2013;25:216-225. 